\title{
Keep the doctor at bay
}

\section{Clean energy initiatives offer a way to realise substantial global health benefits.}

Donald Trump has spent a lot of time talking about how much he likes clean air and water. Yet his plans for the Environmental Protection Agency (EPA) suggest otherwise. He and new EPA head Scott Pruitt have pointed to a desire to roll back a number of Obama-era measures to curb emissions, including the Clean Air and Clean Water Acts and the Clean Power Plan. Trump's first budget proposal includes cuts of $31 \%$ and $5.6 \%$ to the EPA and Department of Energy budgets, respectively, including the elimination of the Advanced Research Projects AgencyEnergy (ARPA-E) ${ }^{1}$. In the face of so many cuts and rollbacks, how can Trump and Pruitt hope to actually keep US air and water clean?

Much of the debate hinges on the relative importance of the environment and jobs (and profits) in the fossil-fuel industry. Less discussed are the health impacts of energy generation infrastructure. This is an important element of the EPA's work, which funds a lot of research into public health protection and improvement. All this work is at risk from future cuts, potentially leaving Americans literally exposed to the harmful effects of burning fossil fuels.

Yet the links between energy and health are global. Power plants discharge toxic pollutants into water systems. Nuclear power stations pose risks of leakage of harmful radioactive products and through long-lived radioactive waste. Extraction of fossil fuels exposes workers to harmful substances, produces toxic wastewater, and runs the risk of accidents such as oil spills that can have long-term health impacts. Even solar panels have environmental health impacts through their manufacture and eventual disposal.

Meanwhile, air pollution was estimated to be responsible for 6.5 million deaths worldwide in $2012^{2}$. The largest contributors to air pollution include particulate matter, nitrogen oxides, carbon monoxide, and sulfur dioxide, with transportation, burning fuels for energy, and burning inefficient and unclean fuels for cooking being major sources. A 2007 study found that lignite, coal, gas and oil were responsible for 78.3 deaths per TWh of electricity generated in Europe; biomass and nuclear caused 18.4 and 0.052 deaths per TWh, respectively ${ }^{3}$. The numbers of serious and minor illnesses attributable to energy sources show orders of magnitude higher rates. To provide context, the EU produced 3,172 TWh of electricity in $2007,55 \%$ of which came from coal, gas and oil ${ }^{4}$. It has also been shown that coal combustion in China contributed to around 366,000 deaths in $2013^{5}$.

Research also increasingly shows that fossil fuel combustion threatens child health and development ${ }^{6}$. Edson Severnini underlines this point in this issue (article no. 17051) in the context of nuclear energy. He shows that air pollution rose following the closure of nuclear power plants by the Tennessee Valley Authority in the wake of the Three Mile Island disaster in 1979 and their replacement by coal-fired power stations. Crucially, he also finds evidence for the deterioration of infant health in those regions affected by power plants. Although public fears about nuclear power may be allayed by decisions to close nuclear plants, the ultimate balance of effects may not be positive.

Energy inequity further compounds health issues. Two new reports from the World Health Organization find that environmental risks were responsible for the deaths of 1.5 million children under five in $2015^{7,8}$. Of these, nearly 570,000 arose from respiratory infections in 2012. Household air pollution caused by solid cooking fuels and ambient air pollution account for over $50 \%$ of lower respiratory infections in children under five in lowincome and middle-income countries. Women are also disproportionately at risk from polluting fuels ${ }^{9}$. At the same time, lack of access to basic or reliable energy services can undermine provision of health-care services.

To think of the clean energy transition only in terms of tackling climate change is to miss such critical issues presented by fossil-fuel-dependent power, heating and transportation systems. As noted by The Lancet, "Tackling climate change could be the greatest global health opportunity of the twenty-first century" 10 . Lives are at stake today, not just at the end of the century. Energy policy needs to more clearly take health impacts into consideration, recognising the important health costs and benefits inherent in any choice about energy infrastructure.
Although there are still environmental health impacts to consider, clean energy technologies present significantly lower risks to health than fossil fuels. Investments in clean energy can thus couple the provision of modern energy sources with savings in healthcare. Stronger links between energy, climate and health policies stand to reap more benefits than thinking of each in isolation.

Agencies like the EPA should be empowered to regulate energy emissions and fuel standards if they are going to make any gains towards cleaning our air and water and improving our health. The EPA occupies a pivotal position between energy and health sectors, which gives it a critical perspective and the ability to bridge the divide. Similarly, agencies like ARPA-E should exist to promote fledgling energy technologies that could provide clean solutions but that the private sector is not yet willing to invest in.

But we also each play a role in broadening out the narrative for energy research and helping make the case for considering the health impacts of energy. This is not to undermine the importance of tackling climate change or to suggest that we should stop discussing its urgency. But more can be done by energy researchers (and journal editors and publishers) to discuss the connections between energy and health and the need to transform our energy system, not just to tackle climate change but to improve the health and wellbeing of everyone. There is an opportunity available in acting together across clean energy, climate change and health. Let's grasp it.

\footnotetext{
References

1. America First: A Budget Blueprint to Make America Great Again (Executive Office of the President of the United States, 2017).

2. World Health Statistics 2012 (WHO, 2012).

3. Markandya, A. \& Wilkinson, P. Lancet 370, 979-990 (2007).

4. Breakdown of Electricity Generation by Energy Source (The Shift Project Data Portal, accessed 16 March 2017); http://go.nature. com/2ndEDLT

5. Burden of Disease Attributable to Coal-Burning and Other Major Sources of Air Pollution in China (Health Effects Institute, 2016).

6. Perera, F. P. Environ. Health Perspect. 125, 141-148 (2017).

7. Don't Pollute My Future! The Impact of the Environment on Children's Health (WHO, 2017).

8. Inheriting a Sustainable World? Atlas on Children's Health and the Environment (WHO, 2017).

9. Burning Opportunity: Clean Household Energy for Health Sustainable Development, and Wellbeing of Women and Children (WHO, 2017).

10. Watts, N. et al. Lancet 386, 1861-1914 (2015).
} 